\title{
Kabir Wealth Code: The combined effect of emotional awareness (EA) and intelligence quotient (IQ)
}

Author List: Azad Kabir, MD MSPH${ }^{1 *}$; Raeed Kabir ${ }^{1}$; Jebun Nahar, PhD $^{1}$; Ritesh Sengar, $\mathrm{MSc}^{1}$

${ }^{1}$ Department of Research and Innovation; Doctor Ai, LLC; 1120 Beach Blvd, Biloxi; MS 39530.

Corresponding author's name and contact information (e-mail address, mailing address, phone number): Azad Kabir, MD, MSPH, ABIM; Doctor Ai, LLC; 1120 Beach Blvd, Biloxi; MS 39530; Email: azad.kabir@gmail.com; Cell: 228-342-6278

\begin{abstract}
:
Background: Intelligence quotient (IQ) is a measure of intellectual ability of performing, comprehension, and learning. Previous studies reported that intelligence measures predict various measures of job performance and income. Emotional awareness (EA) is the measure of emotional capacity to recognize and make sense of one's emotions, as well as those of others. A high level of emotional awareness (EA) indicates one can learn from expressed emotions quickly. Both $I Q$ and $E A$ are important for personal and professional success.
\end{abstract}

Objective: This study tests the hypothesis that the average national income rank is best predicted by the combined effect of the population's average intelligence quotient (one's ability to perform and learn) and emotional awareness (ability to recognize and make sense of emotions).

Method: The population's average intelligence quotient (IQ), emotional awareness (EA), and indices of good governance, which include corruption perception index and educational expenses for each country, were obtained from public data sources. The 
outcome variable was per capita gross national income. All the variables that are statistically significant in univariate analysis were included in the multivariate regression analyses but excluded from the final model if not statistically significant.

Result: The total number of countries included in the final analysis was 81 because of missing values in different variables. Intelligence quotient (IQ) and emotional awareness (EA) were found to be highly correlated, at 0.77 and 0.32 respectively, with the per capita gross national income. The independent effects of intelligence quotient (IQ) and emotional awareness (EA) were found significant in the multivariate model after adjusting for measures of good governance. The $R$ square value for the final multivariate model was 0.82 . The corruption perception index ( $\mathrm{CPI}$ ) and educational expenses were strongly correlated with other measures of good governance such as democracy index, functioning of government, electoral process and pluralism, political participation, and civil liberty, but these variables were found not significant in the multivariate model.

Conclusion: The study concludes the effect of intelligence quotient (IQ) and emotional awareness (EA) are complementary to each other but intelligence quotient (IQ) is a stronger predictor than emotional awareness (EA) for gross national income or wealth. We also find that indicators of good governance, including corruption perception index and educational expenses have important associations with per capita gross national income. This study implies a nation may build more wealth if the educational system focuses on developing emotional awareness in addition to intelligence.

\section{Introduction:}

Intelligence quotient (IQ) is a measure of intellectual ability: comprehension, learning, and performing. IQ tests were developed in Western Europe and the United States during the $20^{\text {th }}$ century, and it is still debatable whether they are fully valid when applied to people on different continents with different social structures, cultures, values, and ways of thinking. What we do know from previous studies is that IQ and related measures predict various measures of job performance and income [e.g., Neisser et. al. (1996)]. Zagorsky (2007) reported using data from the Unites States that each point increase in IQ test scores raises income by between $\$ 234$ and $\$ 616$ per year after holding a variety of factors constant. Lynn and Vanhanen regressed per capital gross domestic product (GDP) against average country IQ for almost every country in the world and reported that IQ is a powerful predictor of absolute GDP. By employing regression analysis, the authors isolated deviant data points, and tried to explain why the individual countries they 
represent at these points in time deviated significantly from the expected trend-line values [Lynn, Richard and Vanhanen, Tatu. (2002)]. There is outlier of the above analysis such as countries with the highest IQs are not always the richest. For example, Japan, Singapore, South Korea and Hong Kong and the other economically advanced countries of East Asia have higher IQs than western countries, but their wealth is mostly lower. This observation suggests that there is another form of intelligence which is not measured by intelligence quotient (IQ) but impacts the national economic growth or GDP.

Emotional awareness (EA) is the capacity to recognize and make sense of one's own emotions and those of others. A high level of emotional awareness (EA) describes attentiveness to the emotional states of people, which is a requirement to learn from expressed emotions quickly. This helps to solve real-life problems, for example by being able to regulate one's emotions or cheer others up when they are feeling low. EA is an important part of emotional intelligence (EI). The other part of $\mathrm{El}$ is to manage one's emotions to handle interpersonal relationships judiciously and empathically. Perhaps, emotional awareness (EA) is a foundation of both conceptions of $\mathrm{El}$, under the assumption that people who are good at experiencing their own emotions are also good at recognizing and understanding other people's emotions. All these characteristics are important for personal and professional success.

Studies on emotional awareness (EA) are scarce, but a previous study suggested that emotional intelligence (EI) has a significant positive effect on subsequent salary levels. It helps individuals to acquire the social capital needed to be successful in their careers [Rode et. al. (2017)]. Another study suggested that the emotionally intelligent worker is more likely to empathize with others leading to a supportive work environment and professional success [Van Rooy et. al. (2004)]. It was also reported that emotion recognition abilities lead to political skills and interpersonal facilitation. This leads to more cooperative, considerate, and helpful team members and eventually to higher annual income [Momm et. al. (2014)].

There is little agreement among experts what El really is. The emotional awareness (EA) may be the first requirement for emotional intelligence. According to the simulation hypothesis, people who are aware of their own emotions are likely to be able to infer other people's emotions [Currie, G. (1996)]. The second part of emotional intelligence is the intelligence which integrate the various emotions, to make "rational" choices for oneself and to predict how others integrate their emotions into plans of action. These abilities are exceedingly important for managers who must coordinate the work of others, conduct negotiations, etc. Neurologists believe that this integration of emotion and innate cognitive 
reflexes into action, by applying it to current tasks, is a major function of the prefrontal cortex.

Human capital is know-how and all those qualities that support worker productivity. The intelligence quotient (IQ) is considered the best indicator of human capital, better than educational measures such as higher degrees and years in school. One limitation of intelligence quotient (IQ) is that it measures complex reasoning skill and ability to learn about the physical world. It does not measure "people skills", which are also needed for efficient work in complex organizations where people interact with one another all the time. There is a need to overcome this limitation of intelligence quotient (IQ) and similar measures, such as standardized school achievement tests, to include measures of people skills. Thus, it is important to investigate whether average national emotional awareness (EA) measures, in addition to measures of intelligence (IQ), can predict a country's wealth as such a hypothesis has not been tested before.

\section{Methods:}

Emotional awareness (EA) data were obtained from Gallup's emotional study which collected people's positive and negative daily experiences based on more than 151,000 interviews with adults in over 140 countries in 2018 [Gallup 2019 Global Emotional Report]. As a measure of emotional awareness (EA), Gallup took the percentage of any country's respondents who said they had experienced the full range of positive and negative emotions on the previous day. The exact yes/no questions used in Gallup's positive and negative experience Index were:

1. Did you feel well-rested yesterday?

2. Were you treated with respect all day yesterday?

3. Did you smile or laugh a lot yesterday?

4. Did you learn or do something interesting yesterday?

5. Did you experience the following feelings during a lot of the day yesterday? How about enjoyment?

6. Did you experience the following feelings during a lot of the day yesterday? How about physical pain? 
7. Did you experience the following feelings during a lot of the day yesterday? How about worry?

8. Did you experience the following feelings during a lot of the day yesterday? How about sadness?

9. Did you experience the following feelings during a lot of the day yesterday? How about stress?

10. Did you experience the following feelings during a lot of the day yesterday? How about anger? [Gallup 2019 Global Emotional Report].

The emotional awareness (EA) used in this study had a mean value of 47 percent (ranging between 36 to 54 ) with a standard deviation of 4.5 .

The study's final model included a total of 81 countries' average population intelligence quotient (IQ) which was collected from the results of several international studies [IQ data by country; Lynn et. al. (2002); Rindermann H; Khaleefa et. al. (2007); Ahmad et al. (2008); Lynn (2008); Meisenberg et. al. (2011)]. The intelligence quotient used in this study had a mean value of 87.5 points with a standard deviation of 12.6 (range from 60 to 108). The per capita gross national income included in this study was obtained for the year 2019 from the World data website which is simulated from the World Bank, International Monetary Fund and the OECD countries report available in their websites. Average per capita gross national income was calculated by dividing all annual incomes and profits by the size of the country's population. Income is usually not normally distributed, neither at the individual nor the aggregate level. It is positively skewed. Therefore, to use parametric statistics, the study used a logarithmic transformation of gross national income to bring it closer to a symmetric Gaussian distribution.

The other factors that can explain per capita gross national income were indices of good governance, such as the democracy index, electoral process, and pluralism, functioning of government, political participation, civil liberties, and corruption perception index. The national education expense was used in the analysis to explore its impacts on national wealth building. One can assume that a nation with higher wealth will spend more on educational infrastructure building which might lead to higher national wealth. However, this study evaluates whether both the intelligence quotient $(\mathrm{IQ})$ and educational expense stands out as a significant factor for national wealth or not. These data about the measures of good governance were compiled by the Economist Intelligence Unit and obtained from the World Population Review [Economist Intelligence Unit: Democracy 
index data] website and the data related to corruption perception index (CPI, 2020) were obtained from the Transparency International website [The 2020 CPI Report]. The CPI score was measured on a scale of zero (highly corrupt) to one hundred (very clean).

All these data sets were merged by country using Python data analysis software. Subsequently, a master data file was built which had the population's log-transformed average national income, emotional awareness (EA), intelligence quotient (IQ), per capita gross national income, democracy index, electoral process, pluralism, functioning of government, political participation, education expenses, and corruption perception index (CPI). The outcome variable for this study was the log-transformed average per capita national income of a country. Correlation and multivariate regression analyses were done using Stata statistical analysis software. Variables that were statistically significant in univariate analysis were included in the multivariate model but excluded from the final model if they lacked statistical significance in the multivariate model. We did not impute any missing values of the key study variables such as average annual income, emotional awareness (EA) and intelligence quotient (IQ) scores, leading to a decreased sample size from 140 to 81 . However, missing data for educational expenses, corruption perception index, and other measures of good governance were replaced with their average value.

\section{Results:}

The total number of countries included in the study was 102 because average intelligence quotient scores were not available for the others. Of those 102 countries, twenty-one (21) were excluded from the analysis because of missing data for emotional awareness (EA). Thus, the study included eighty-one (81) countries for the final data analysis. Countries were ranked by per capita gross national income, and data for every fifth are shown in Table 1.

Countries with the highest IQs are not always the richest. For example, Japan (IQ:105; EA:47; GNI: 36784), Singapore (IQ:108; EA:36; GNI: 25,561 not shown in table), South Korea (IQ:106; EA:42; GNI: 13,759, not shown in table) and Hong Kong (IQ:108; EA:46; 25,419, not shown in table) and the other economically advanced countries of East Asia have higher IQs than western countries, but their wealth is mostly lower. This finding suggests that emotional awareness plays a significant role in national wealth building as western countries have higher emotional awareness (EA). Though China has an average IQ of 104 and EA of 46 , its per capita gross national income is $\$ 1,374$ indicating that intelligence quotient (IQ) and emotional awareness (EA) do not explain all variability of 
national wealth. China, for example, has a low democracy index of 2.26 (out of 10), low corruption perception index of 42 (higher is better, with highest being 100), and average educational expenses of $\$ 27$ (USA has $\$ 1,909$ ).

Table 1. Every fifth countries ranked from $1^{\text {st }}$ to $80^{\text {th }}$ by the per capita gross national income (GNI): Demonstrating the combined effect of emotional awareness (EA) and intelligence quotient (IQ), educational expense and Corruption Perception Index (CPI).

\begin{tabular}{lccccc}
\hline \multicolumn{1}{c}{ Country } & EI & IQ & $\begin{array}{c}\text { Education } \\
\text { expenditure }\end{array}$ & CPI & $\begin{array}{c}\text { Income rank } \\
\text { (GNI) }\end{array}$ \\
\hline Luxembourg & 50 & 99 & 2,286 & 80 & 1 \\
\hline Sweden & 49 & 99 & 2,337 & 85 & 5 \\
\hline United Kingdom & 49 & 100 & 1,443 & 77 & 10 \\
\hline Canada & 54 & 101 & 1,657 & 77 & 15 \\
\hline Spain & 53 & 97 & 884 & 62 & 20 \\
\hline Portugal & 50 & 95 & 724 & 61 & 25 \\
\hline Trinidad and Tobago & 50 & 85 & 274 & 40 & 30 \\
\hline Poland & 46 & 97 & 298 & 56 & 35 \\
\hline Malaysia & 48 & 93 & 273 & 51 & 40 \\
\hline Botswana & 43 & 72 & 348 & 60 & 45 \\
\hline Ecuador & 54 & 83 & 68 & 39 & 50 \\
\hline Ukraine & 38 & 95 & 83 & 33 & 55 \\
\hline Sri Lanka & 47 & 79 & 30 & 38 & 60 \\
\hline Djibouti & 45 & 63 & 73 & 27 & 65 \\
\hline Sudan & 47 & 70 & 14 & 16 & 70 \\
\hline Chad & 45 & 65 & 10 & 21 & 75 \\
\hline Sierra Leone & 45 & 71 & 8 & 33 & 80 \\
\hline
\end{tabular}

Table 2 shows that there is virtually no correlation between IQ and EA in this sample of countries, with a correlation coefficient of 0.04. This shows that IQ and EA measure completely different characteristics. However, both are related to national income. The independent effect of intelligence quotient (IQ) and emotional awareness (EA) was significant in the univariate ( $r$ 's $=0.77$ and $0.32 ; R$ square value of 0.59 and 0.10 ; respectively). Corruption perception index (CPI) and gross national income were found 
highly correlated with measures of good governance such as democracy index, electoral process \& pluralism, functioning of government, political participation, educational expenses, and civil liberties.

Table 2: Correlation matrix of variables which are potential candidates for the multivariate analysis.

\begin{tabular}{|c|c|c|c|c|c|c|c|c|c|c|c|}
\hline & $\begin{array}{c}\text { LOG } \\
\text { GNI }\end{array}$ & GNI & IQ & EA & DI & EPP & FG & PP & CL & CPI & EE \\
\hline LOG National Income & 1.00 & & & & & & & & & & \\
\hline Gross National Income (GNI) & $0.87^{*}$ & 1.00 & & & & & & & & & \\
\hline Intelligence Quotient (IQ) & $0.77^{\star}$ & $0.59^{*}$ & 1.00 & & & & & & & & \\
\hline Emotional Awareness (EA) & $0.32^{*}$ & $0.32^{*}$ & 0.04 & 1.00 & & & & & & & \\
\hline Democracy Index (DI) & $0.72^{*}$ & $0.60^{*}$ & $0.55^{*}$ & $0.36^{*}$ & 1.00 & & & & & & \\
\hline $\begin{array}{l}\text { Electoral process \& } \\
\text { Pluralism (EPP) }\end{array}$ & $0.59^{\star}$ & $0.46^{\star}$ & $0.47^{*}$ & $0.31^{*}$ & $0.94^{*}$ & 1.00 & & & & & \\
\hline $\begin{array}{l}\text { Functioning of Government } \\
\qquad(\mathrm{FG})\end{array}$ & $0.71^{*}$ & $0.59^{*}$ & $0.59^{*}$ & $0.39^{*}$ & $0.93^{*}$ & $0.84^{*}$ & 1.00 & & & & \\
\hline Political Participation (PP) & $0.67^{*}$ & $0.57^{*}$ & $0.51^{*}$ & $0.31^{*}$ & $0.90^{*}$ & $0.81^{*}$ & $0.80^{*}$ & 1.00 & & & \\
\hline Civil Liberty (CL) & $0.71^{*}$ & $0.57^{*}$ & $0.54^{*}$ & $0.31^{*}$ & $0.97^{\star}$ & $0.93^{*}$ & $0.88^{*}$ & $0.85^{\star}$ & 1.00 & & \\
\hline $\begin{array}{l}\text { Corruption Perception Index } \\
\text { (CPI) }\end{array}$ & $0.85^{*}$ & $0.76^{\star}$ & $0.67^{*}$ & $0.27^{*}$ & $0.82^{*}$ & $0.68^{*}$ & $0.84^{*}$ & $0.73^{\star}$ & $0.80^{*}$ & 1.00 & \\
\hline Educational Expenses (EE) & $0.60^{*}$ & $0.36^{*}$ & $0.49^{\star}$ & 0.06 & $0.33^{*}$ & $0.27^{*}$ & $0.32^{*}$ & $0.27^{\star}$ & $0.38^{*}$ & $0.49^{*}$ & 1.00 \\
\hline
\end{tabular}

All variables in Table 2 that have a significant correlation with log-transformed per capita gross national income were used for multivariate regression analysis. Variables that were not statistically significant were excluded from the multivariate analysis in a step-by-step fashion. The independent effects of intelligence quotient (IQ) and emotional awareness (EA) were found strongly significant after inclusion of measures of good governance which includes corruption perception index and educational expenses (Table 3). All other measures of good governance (except corruption perception index and educational 
expenses) were excluded from the multivariate regression because their effects were found not statistically significant.

The $R$ square value for the final multivariate model with only intelligence quotient, (IQ) and emotional awareness (EA) was .67 indicating that these two variables alone explain $67 \%$ of the variability of per capita gross national income. Table 3 shows the most predictive model, with intelligence quotient (IQ), emotional awareness (EA), corruption perception index and educational expenses as predictors and an $\mathrm{R}$ square value of .82 . This indicates that the effects of (IQ and EA are the key to explain a country's income growth independent of other conditions that can impact the per capita average income.

According to the current study, if emotional intelligence (EA) scores can be increased by 5 points through training of the whole nation, while holding intelligence quotients constant at 100 , the effect size will change $(5) \times(0.058)=0.29$; [beta coefficient of emotional awareness (EA)]. Corruption perception index (CPI) was highly correlated with all other measures of good governance such as the democracy index, functioning of government, electoral process \& pluralism, political participation, civil liberty. These variables were excluded from the final multivariate model as they were found not significant. In Table 3 you show only the final model. It would be a lot more elegant to present several models, each with IQ and EA as predictors and each model having only one additional predictor such as corruption or democracy. This can show whether effects of either IQ or EA are in part mediated by one or another of these other variables.

Table 3. The combined effect of Intelligence Quotient (IQ) and Emotional Awareness (EA) on the log transformed gross national income: A multivariate analysis $(n=81)$

\begin{tabular}{lccccc}
\hline \multicolumn{1}{c}{ Variables } & Coefficient & $\begin{array}{c}\text { Standard } \\
\text { Error }\end{array}$ & $\begin{array}{c}\text { Lower } \\
\text { Limit }\end{array}$ & $\begin{array}{c}\text { Upper } \\
\text { Limit }\end{array}$ & $\begin{array}{c}\text { P- } \\
\text { value }\end{array}$ \\
\hline Intelligence Quotient (IQ) & 0.041 & 0.009 & 0.022 & 0.060 & $<0.001$ \\
\hline Emotional Awareness (EA) & 0.058 & 0.018 & 0.021 & 0.094 & $<0.003$ \\
\hline Educational Expenses & 0.001 & 0.0004 & 0.0006 & 0.002 & $<0.001$ \\
\hline Corruption Perception Index (CPI) & 0.036 & 0.006 & 0.025 & 0.048 & $<0.001$ \\
\hline
\end{tabular}




\begin{tabular}{|c|c|c|c|c|c|}
\hline Constant & -0.022 & 1.146 & -2.305 & 2.262 & $<0.985$ \\
\hline
\end{tabular}

R Square value $=0.82$

Table 4 shows the impact of wealth increase when countries with emotional awareness $(E A)$ is increased among the group with the higher intelligence quotient (IQ) tertile. Countries with the highest (third) quartile of intelligence quotient (IQ), the average income was $\$ 10,373, \$ 32,473$, and $\$ 31,529$ for the lowest, middle, and highest tertiles of emotional awareness (EA), respectively. However, increase of income due to increase in emotional awareness is not as drastic among the group with lowest intelligence quotient (IQ). Countries with the lowest (first) quartile of intelligence quotient (IQ), the average income was $\$ 1,122, \$ 1,396$, and $\$ 3,886$ for the countries with lowest, middle, and highest tertiles of emotional awareness (EA), respectively. Again, there are increasing trends of income potential among the countries with tertiles of intelligence quotient (IQ) and emotional awareness (EA) separately. The average income for the countries with lowest tertiles of intelligence quotient (IQ) was $\$ 1,582$ and highest tertiles was $\$ 24,792$. Again, the average income for the countries with lowest tertiles of emotional awareness (EA) was $\$ 4,312$ and highest tertiles was $\$ 17,680$.

Table 4: Average wealth distribution among the tertiles of emotional awareness (EA) and intelligence quotient (IQ).

$\begin{array}{ccccc}\text { Quartiles } & \text { EA Tertile } 1 & \text { EA Tertile } 2 & \text { EA Tertile } 3 & \text { Total } \\ & (36-46) & (46-49) & (49-54) & \\ \text { IQ Tertile 1 } & \$ 1,122 & \$ 1,396 & \$ 3,886 & \$ 1,582 \\ \text { (60-83) } & (n=16) & (n=10) & (n=4) & (n=30) \\ \text { IQ Tertile 2 } & \$ 3,923 & \$ 6,104 & \$ 11,365 & \$ 7,698 \\ \text { (83-95.5) } & (n=9) & (n=4) & (n=11) & (n=24) \\ \text { IQ Tertile 3 } & \$ 10,373 & \$ 32,473 & \$ 31,529 & \$ 24,792 \\ \text { (95.5-108) } & (n=9) & (n=9) & (n=9) & (n=27) \\ \text { Total } & \$ 4,312 & \$ 14,376 & \$ 17,680 & \$ 11,131 \\ (n=34) & (n=23) & (n=24) & (n=81)\end{array}$




\title{
Equation 1: Regression model to predict average national income:
}

\author{
LogPerCapitaGrossNationalIncome ${ }_{i}$ \\ $=-0.022+0.041 *$ IntelligenceQuotient $_{i}+0.058 *$ EmotionalAwareness $_{i}$ \\ $+0.001 *$ EducationalExpense $_{i}+0.036 *$ CorruptionPerceptionIndex $_{i}+\varepsilon_{i}$
}

Equation 1 shows any country's per capita gross income (log transformed) can be predicted reasonably well using the model that includes emotional awareness (EA) and intelligence quotient (IQ), educational expenses, and corruption perception index (CPI), the latter being measures of good governance that are themselves likely to be affected by the psychological measures of IQ and EA. This model can be used to evaluate the return on investments for different educational and training programs to improve emotional awareness (EA) and intelligence quotient (IQ).

\section{Discussion:}

It is important to understand the conditions that predict country-level wealth or average income. If such causally effective conditions can be identified, the country can achieve wealth growth by allocating resources to increasing strength in that dimension. This study found the human capital such as intelligence quotient (one's ability to perform and learn) and emotional awareness (emotional ability to recognize and make sense of emotions) to be the most important factor in predicting the wealth of countries based on gross national income (GNI). More specifically, human capital is the important factor for GNI, and intelligence quotient (IQ) and emotional awareness (EA) measure two different aspects of human capital.

The significant effects of emotional awareness (EA), and intelligence quotient (IQ) opens a new door to understanding how nations build wealth, with effects of psychological traits that are in part mediated by various indicators of good governance such as educational expenses and control of corruption. One important aspect is that modern secular education systems are conceived to develop children's thinking skills, not to develop their interpersonal skills. This study's findings indicate that the teaching of emotional awareness, which is social skills and empathy, should be included in the school curriculum for the benefit of economic development. Emotional awareness (EA) scores are easier to measure using Gallup's ten (10) questions [Gallup 2019 Global Emotional Report] than measuring emotional intelligence (EI) scores with tests of uncertain validity and reliability. It is important to develop more valid El tests that predicts national wealth 
gain. There are different conceptions of El both in the literature and in the tests used to measure this trait. Some treats it as a bunch of desirable personality traits that are good for happiness and social harmony. Others treat it as a set of abilities, but these abilities are difficult to measure. The current study indicates an El focused on gaining wealth should be developed rather than personality or other abilities. Macroeconomic consequences have so far not been investigated in extant emotional intelligence (EI) research. Thus, one hidden key to a country's economic success may be emotional awareness (EA) or emotional intelligence, which explains the largest variability of per capita income after intelligence measured as IQ.

In addition, the near-zero correlation between the indicators of intelligence (IQ) and emotional awareness (EA) shows that both are measuring two different characteristics. This non-correlation is indeed remarkable because most country-level variables correlate with wealth and IQ. Using univariate analyses, this study found that the correlations of intelligence quotient (IQ) and emotional awareness (EA) with gross national income are 0.77 and 0.32 respectively, both with statistically significant $p$ values $(<0.05)$. It is also important to note that the R-square value of Intelligence quotient (IQ) regressed on log transformed gross national income is 0.59 , and the R-squared value of emotional awareness (EA) regressed on log transformed gross national income is merely 0.10 . All these correlation coefficients and $R$ square values indicate that $I Q$ and $E A$ are complementary to each other, but intelligence quotient (IQ) has a much stronger effect on gross national income than emotional awareness (EA). The $R$ square value for the multivariate model with only intelligence quotient, (IQ) and emotional awareness (EA) was 0.67 . This means that the two human capital effects explored here explain more of the variability in gross national income than any other variable in this study except for corruption, which is itself strongly related to IQ and to EA. Thus, this study explicitly offers a theoretical view that sees human capital as the most important source of national wealth and allother variables, such as corruption, democracy, educational expense, and other governance indicators have a bidirectional relationship. They are determined in large part by the levels of IQ and EA in the country, and they are part of the processes that translate human capital into national wealth: Human capital $\rightarrow$ effective institutions $\rightarrow$ national wealth $\rightarrow$ educational institute $\rightarrow$ human capital.

This is the hidden key that elucidates the nuanced relationship among income, intelligence quotient (IQ), and emotional awareness (EA) at the national level. The strength of such correlations depends on the accuracy with which the causally important constructs are measured. The measurement of intelligence is rather precise, in part because the construct is easily testable and in part because of the enormous effort that 
psychologists and educators have invested in improved tests. There is perhaps reason to believe that the important underlying construct of "emotional intelligence" is far more difficult to measure, and that measures such as the 10 Gallup questions may not be a very precise measure of the construct. In consequence, the effect of emotional intelligence most likely is underestimated.

Collectively, these findings indicate that a country with a high intelligence quotient (IQ) and high emotional awareness (EA) will most likely achieve greater national income or wealth than a country with high intelligence quotient (IQ) and low or moderate emotional awareness (EA). Similarly, a country with a low intelligence quotient (IQ) and high emotional awareness (EA) will likely attain more income and wealth than a country with low intelligence quotient (IQ) and low emotional awareness (EA). A similar finding was reported at the individual level, where emotional intelligence (EI) can be more important to individuals with low intelligence quotient (IQ) [Côté et. al. (2006)].

Since the average national income level exists as a representative value for an entire country, other unified, representative variables can be used to explain average national income. In a multivariate analysis, the most predictive model included four variables: the effect of intelligence quotient (IQ), emotional awareness (EA), educational expenditure, and the corruption perception index (CPI). All four variables were highly significant, and the model had an R-squared value of 0.82 , meaning that these four variables were able to explain $82 \%$ of the variance in gross national income. With a country's average income depending on a countless number of unknown variables, it is surprising that just four variables can capture so much of the underlying mechanism. That is why just these four variables can be considered as the hidden key of wealth for any nation. The reason for this high $\mathrm{R}$ squared is most likely that each of these variables has high correlations with GNI. The reason for these high correlations is most likely that there is bidirectional causation for each of these variables. They all cause countries to be rich, but they are also boosted by high prosperity.

Given the study utilized per capita national income as the criterion, the factor that can confound the national income is good governance is a plausible confounding factor or mediator. Good governance was measured as the democracy index, electoral process, and pluralism, functioning of government, political participation, civil liberty, educational expense, and corruption perception index (CPI). This is best conceptualized not as a matter of confounding, but of mediation. Human beings create wealth, and human beings create efficient institutions. Human capital, measured by IQ and EA, is the ultimate cause, and some of the effects of human capital on wealth are mediated by institutions. In 
consequence, all these variables are highly correlated (Table 2). However, the final model did not include the democracy index, political participation, electoral process \& pluralism, functioning of government, and civil liberty, which were likely explained by the corruption perception index and educational expense. They dropped out of the regression models simply because they are not only conceptually related, but they have high correlations with each other. They explained each other's contribution, and therefore only the most relevant and best measured governance indicators remain in the models. The gross national income depends on the corruption perception index, and educational expense after adjusting for the intelligence quotient (IQ) and emotional awareness (EA).

The significant effect of educational expenses is an important though unsurprising finding of the study. Education is a fundamental requirement for economic growth and sustainable prosperity. Without proper educational infrastructure such as smaller class sizes, creative classrooms, availability of books and supplies, interactive digital technologies, natural lighting and proper ventilation, experienced teachers, drug-free environments, and students' food security, the teaching and learning process will be impaired leading to poor educational outcomes. Therefore, we may be dealing with bidirectional causation. It is possible that the rich countries being rich because of high educational expenses, they have high educational expenses because they are rich and can afford them. This higher educational expense possibly led to higher wealth. In a regression model that treats educational expenses as a cause rather than a consequence of wealth, this can easily lead to a possible conclusion that educational expenses cause wealth. Thus, the direction of causality remains unproven at the national level. However, the index of good governance is also fundamental for income growth, which is supported by other studies [Mira et. al. (2017)].

Given the estimates used in this study were average national income, intelligence quotient (IQ), and emotional awareness (EA), we can hypothesize that any group of individuals, in any country, with high intelligence quotient (IQ) and high emotional awareness (EA) can reach a higher potential of income than those of comparatively high intelligence quotient (IQ) and moderate or low emotional awareness (EA). Here again, the obvious example are different minority and immigrant groups in countries like the US, Britain, and other western countries, where wealth and other social outcomes seem to be predictable quite well by intelligence quotient (IQ), and perhaps also by emotional intelligence (EA) if valid measures of the latter construct can be found. Obtaining a representative sample that would reflect the average incomes for a certain group of populations from the whole world might not change the study conclusion given the remarkably high $\mathrm{R}$ square value (0.82) of the final model at the national level. 
A previous study reported that emotional intelligence (EI) predicts individuals' salaries 10 to 12 years post workforce entry [Rode et. al. (2017)]. This time lag may be the reason behind national averages (or averages of larger groups within countries) showing strong correlations with income. This finding implies that a nation can build more wealth if its schools try to develop emotional awareness (EA) in addition to intelligence (IQ).

Kovas et al. reported that genes are responsible for stability of IQ across the lifespan [Kovas et al. (2007)]. However, according to the "Flynn effect" there has been a rise in IQ scores over time [Trahan et. al. (2014)]. The current study also supports the Flynn effect because most nations increased their average wealth or income throughout the period when their IQs were rising. This is possibly due to intensified schooling and other changes that promote cognitive and social skills leading to rising intelligence quotient (IQ) and possibly emotional awareness (EA). It is possible that economically advanced nations have educational systems that are highly efficient at raising $I Q$, and perhaps it will be difficult to boost IQ even more. Therefore, the Flynn effect, and the evidence for an end of Flynn effects in advanced countries during the last few decades. Because of the enormous educational expansion over the last century, there is reason to believe that all that can be achieved with modern education to raise IQ has been achieved already. But emotional intelligence is not trained in school, and there may still be possibilities to raise it if only we can figure out how to teach children to become emotionally aware and emotionally intelligent. Previous randomized experimental study also suggests that emotional intelligence can be enhanced through training and development [Gilar-Corbial et. al. (2019)]. In such cases, improving emotional awareness (EA) in addition to intelligence quotient (IQ) should be one of the cornerstones of academic training in school.

The current study finding is much more than just a predictive model to explain any country's wealth. The final multivariate model draws attention to four dimensions of a nation that can be improved upon. It suggests that the way to increase any country's wealth and improve its standing on the world stage is to increase the population's intelligence (IQ) and emotional awareness (EA), and to increase educational expenditure and reduce corruption.

\section{Limitations:}

Intelligence quotient (IQ) measurement used in the study was a conventional measurement scale. It is the concept of intelligence and the specifics of its measurement that is sometimes difficult to apply to people from different cultures. The current study 
cannot prove causality as it used cross-sectional data. In addition, the study findings can be extrapolated only to a national or group level, not individual level given it used national averages. To find the causal relationship at the individual level, further studies are needed where IQ and EA are assessed periodically starting at a young age and wealth or income is recorded at a later time.

\section{Conclusion:}

The study concludes the effect of intelligence quotient (IQ), and emotional awareness (EA) are complementary to each other, but intelligence quotient (IQ) is a stronger predictor than emotional awareness (EA) of per capita gross national income. The study also found that good governance, like control of corruption and educational expenses, is independently related to national income. This study implies a nation may build more wealth if educational institutes focus on developing emotional awareness (EA) in addition to intelligence (IQ). Future studies involving molecular genetics, neuroscience and economics are needed to investigate whether there is a causal effect of emotional awareness (EA) or emotional intelligence (EI) and intelligence quotient (IQ) on an individual's annual income.

Conflict of Interest: Authors have no conflict of interest to disclose.

Acknowledgement: Professor Gerhard Meisenberg, Department of Biochemistry; Ross University, School of Medicine; Dominica provided critical assessments of the research and helped improve its content.

\section{References:}

Ahmad, R., Khanum, S. J., Riaz, Z., Lynn, R. (2008). Gender Differences in Means and Variance on the Standard Progressive Matrices in Pakistan. Mankind Quarterly, 49(1), 50-57. doi:10.46469/mq.2008.49.1.4

Côté, S., Miners, C. T. H. (2006). Emotional Intelligence, Cognitive Intelligence, and Job Performance. Administrative Science Quarterly, 51(1), 1-28. doi:10.2189/asqu.51.1.1 
Currie, G. (1996). Simulation-theory, theory-theory and the evidence from autism. In: P. Carruthers \& P.K. Smith (eds.), Theories of Theories of Mind, pp. 242-256. Cambridge Univ. Press

The 2020 CPI Report by Transparency International. https://www.transparency.org/en/cpi/2020/index/nzl

Economist Intelligence Unit: Democracy index data. <https://worldpopulationreview.com/country-rankings/democracy-countries> Gallup 2019 Global Emotional Report. https://www.gallup.com/analytics/248906/gallupglobal-emotions-report-2019.aspx

Gilar-Corbi R, Pozo-Rico T, Sánchez B, Castejón JL. (2019) Can emotional intelligence be improved? A randomized experimental study of a business-oriented El training program for senior managers. PLoS One. 14(10):e0224254. Published 2019 Oct 23. doi:10.1371/journal.pone.0224254

IQ data by country. https://www.worlddata.info/iq-by-country.php

Khaleefa, O., and Lynn, R. (2008). A Study of Intelligence in the United Arab Emirates. Mankind Quarterly, 49(1), 58-64. doi:10.46469/mq.2008.49.1.5

Kovas Y., Haworth C. M., Dale P. S., Plomin R. (2007) The genetic and environmental origins of learning abilities and disabilities in the early school years. Monographs of the Society for Research in Child Development. 72:vii, 1-144.

Lynn, Richard and Abdalla, S.E.-G \& Al-Shahomee, Alsedig. (2008). Norms for the verbal WISC-R for Libya. Mankind Quarterly. 49. 292-300.

Lynn, Richard and Vanhanen, Tatu. (2002); IQ and the Wealth of Nations; Praeger Publishers, Westport, Connecticut; 298pp. ISBN 0-275-97510-X

Momm, T., Blickle, G., Liu, Y., Wihler, A., Kholin, M., \& Menges, J. I. (2014). It pays to have an eye for emotions: Emotion recognition ability indirectly predicts annual income. Journal of Organizational Behavior, 36(1), 147-163. doi:10.1002/job.1975

Meisenberg, G., \& Lynn, R. (2011). Intelligence: A Measure of Human Capital in Nations. Journal of Social, Political, and Economic Studies, 36, 421. 
Mira, R, Hammadache, A (2017) Good Governance and Economic Growth: A Contribution to the Institutional Debate about State Failure in Middle East and North Africa, Asian Journal of Middle Eastern and Islamic Studies, 11:3, 107-120, DOI: 10.1080/25765949.2017.12023313

Neisser, U., Boodoo, G., Bouchard, T. J., Jr., Boykin, A. W., Brody, N., Ceci, S. J., ... Urbina, S. (1996). Intelligence: Knowns and unknowns. American Psychologist, 51(2), 77-101. doi:10.1037/0003-066x.51.2.77, Page 82-83

Richard Lynn and Tatu Vanhanen. (2002) IQ and the Wealth of Nations. Praeger Publishers, Westport, CT; ISBN 0-275-97510-X

Rindermann H. (2007) The g-factor of international cognitive ability comparisons: the homogeneity of results in PISA, TIMSS, PIRLS and IQ-tests across nations. European Journal of Personality. 21(5):667-706. doi:10.1002/per.634

Rode, J.C., Arthaud-Day, M.L., Ramaswami, A., \& Howes, S. (2017). A time-lagged study of emotional intelligence and salary. Journal of Vocational Behavior, 101: 77-89. DO - 10.1016/j.jvb.2017.05.001

Trahan LH, Stuebing KK, Fletcher JM, Hiscock M. (2014)The Flynn effect: a metaanalysis. Psychol Bull. 140(5):1332-1360. doi:10.1037/a0037173

Van Rooy, D. L., \& Viswesvaran, C. (2004). Emotional intelligence: A meta-analytic investigation of predictive validity and nomological net. Journal of Vocational Behavior, 65(1), 71-95. doi:10.1016/s0001-8791(03)00076-9

Zagorsky, J. L. (2007). Do you have to be smart to be rich? The impact of IQ on wealth, income and financial distress. Intelligence, 35(5), 489-501.

https://doi.org/10.1016/j.intell.2007.02.003 